\title{
Ultrasound-guided esophageal occlusion during rapid sequence induction
}

\author{
Michael Byas-Smith, MD • Jeffrey R. Prinsell Jr, MD
}

Received: 27 September 2012/ Accepted: 21 November 2012/Published online: 20 December 2012

(c) Canadian Anesthesiologists' Society 2012

\section{To the Editor,}

In 1961, Dr. B.A. Sellick demonstrated cricoid pressure (CP), a technique used for esophageal occlusion to prevent gastric regurgitation during tracheal intubation. ${ }^{1}$ The "Sellick Maneuver" has since become common practice during induction of anesthesia when risk of regurgitation is suspected. Recent investigations refute the presumed benefits of this maneuver. Magnetic resonance imaging and computerized axial tomography scanning show that esophageal occlusion with CP may be unreliable. ${ }^{2,3}$

While the Sellick technique may be unreliable, ${ }^{4,5}$ the threat of oral pharyngeal aspiration cannot be ignored in patients undergoing rapid sequence induction. ${ }^{6}$ Hence, it is clinically important to ascertain more reliable methods to reduce the risk of this complication. We present a four-step ultrasound (US)-guided method that has the potential to occlude the esophagus reliably during rapid sequence induction

The following steps are required to perform this technique: Step 1: Identify surface landmarks, cervical cartilages, and muscles. Step 2: Identify the position of the esophagus relative to the surrounding anatomy via standard US probing. The esophagus may be located either to the left or to the right of the trachea (most commonly on the left), typically at four or seven o'clock in the crosssectional view. Step 3: Apply the standard Sellick maneuver to occlude the esophagus or to serve as a backstop to prevent

M. Byas-Smith, MD $(\bowtie) \cdot$ J. R. Prinsell Jr, MD

Emory University School of Medicine, Atlanta, GA, USA

e-mail: michael.byas-smith@emory.org medial migration of the esophagus if pressure is applied laterally. Step 4: If there is inadequate compression of the esophageal lumen, apply gentle pressure with the US probe to maintain $\mathrm{CP}$ and to compress the esophagus lateralmedially until the internal lumen is occluded. The images in the Figure (panels A and B) show how this clinical end point is accomplished with a thumb-shaped transducer (SonoSite S-nerve, C11x/8-5 MHz Transducer, Sonosite, Seattle, WA, USA).

This four-step technique allows for verification of esophageal orientation and occlusion during rapid sequence induction via the standard Sellick maneuver or by using US assistance. In addition to real-time evaluation of esophageal occlusion, inadvertent collapse of the trachea can be detected at the point when pressure is applied. This approach could supplant the blind technique currently practiced, since the esophagus is easy to identify using standard US equipment and the procedure is easy to apply. In our practice, foreknowledge of the position of the esophagus prior to rapid sequence induction is useful to predict the likelihood of effective esophageal occlusion with a standard CP application and also to recognize when lateral compression is necessary to occlude the esophageal lumen. Our anecdotal experience suggests that most patients have no vital tissues lying between the skin and the esophagus when the esophagus deviates laterally to the cartilage either at or below the level of the $\mathrm{C} 6$ vertebra. We recognize that the efficacy of the standard Sellick maneuver and our modified approach may be compromised in patients with large goiter formation or thickened esophageal musculature or when the esophagus is deep to the surface anatomy. Observational studies are warranted to confirm the efficacy of this technique.

Competing interests None declared. 

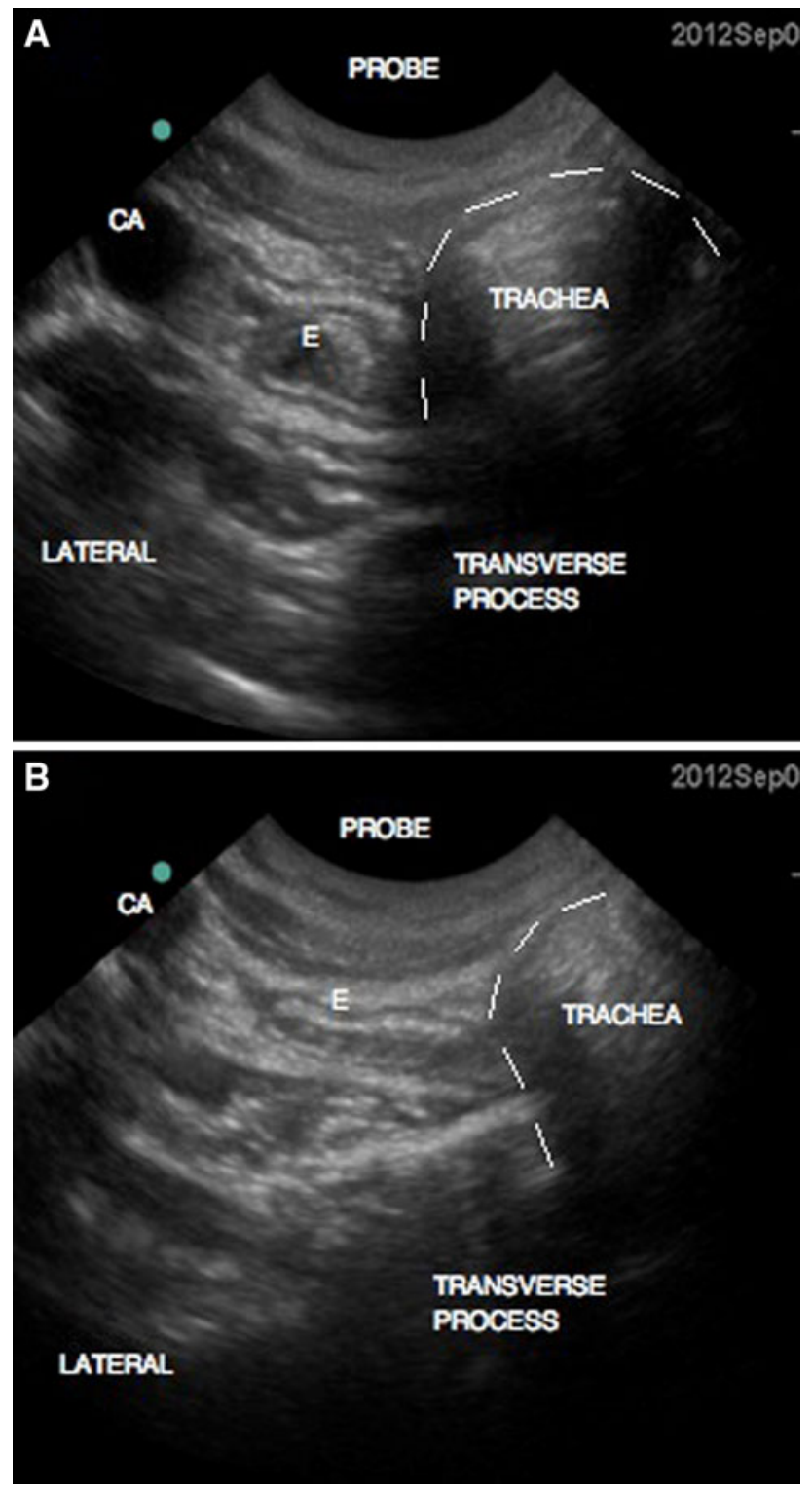

Figure Panel A) Traditional cricoid pressure (CP) is applied to provide a firm "backstop" medial to the esophagus. Panel B) Gentle pressure is applied by the ultrasound probe and directed posteriorly, thereby occluding the esophagus

\section{References}

1. Sellick BA. Cricoid pressure to control regurgitation of stomach contents during induction of anaesthesia. Lancet 1961; 2: 404-6.
2. Boet $S$, Duttchen $K$, Chan $J$, et al. Cricoid pressure provides incomplete esophageal occlusion associated with lateral deviation: a magnetic resonance imaging study. J Emerg Med 2012; 42: 606-11.

3. Rice MJ, Mancuso AA, Gibbs C, Morey TE, Gravenstein N, Deitte $L A$. Cricoid pressure results in compression of the postcricoid hypopharynx: the esophageal position is irrelevant. Anesth Analg 2009; 109: 1546-52.

4. Smith KJ, Dobranowski J, Yip G, Dauphin A, Choi PT. Cricoid pressure displaces the esophagus: an observational study using magnetic resonance imaging. Anesthesiology 2003; 99: 60-4.

5. Neilipovitz DT, Crosby ET. No evidence for decreased incidence of aspiration after rapid sequence intubation. Can J Anesth 2007; 54: 748-64.

6. Ellis DY, Harris T, Zideman D. Cricoid Pressure in emergency department rapid sequence tracheal intubations: a risk-benefit analysis. Ann Emerg Med 2007; 50: 653-65. 